\title{
Antioxidant Activity of Infertile Egg Residue From The Hatching Industry by Giving Chitosan During Different Storage Periods
}

\author{
1Evo Tenri Ubba, ${ }^{2}$ Effendi Abustam and ${ }^{2}$ Nahariah
}

${ }^{1}$ Postgraduate of Animal Science Department, University of Hasanuddin, Makassar, South Sulawesi, Indonesia

${ }^{2}$ Animal Science Department, University of Hasanuddin, Makassar, South Sulawesi, Indonesia

Correspondence Author: Evo Tenri Ubba. Postgraduate of Animal Science Department, University of Hasanuddin, Makassar, South Sulawesi, Indonesia Tel: +6282188335290

Received date: 23 July 2018, Accepted date: 10 October 2018, Online date: 15 October 2018

Copyright: (C) 2018 Evo Tenri Ubba et al., This is an open-access article distributed under the terms of the Creative Commons Attribution License, which permits unrestricted use, distribution, and reproduction in any medium, provided the original author and source are credited.

\begin{abstract}
The number of infertile eggs is quite a lot in the hatchery industry. These eggs are usually removed, but infertile eggs can be sold as consumption eggs and for ingredients in processing food products. However, consumption of infertile eggs is still low in the community. Infertile eggs are susceptible to damage due to warming during the incubation period carried out by the hatchery industry. Damage can be prevented in the presence of antioxidants. Chitosan can act as an antioxidant with the ability to reduce the activity of free radicals. This research aims to analyze the antioxidant activity and physical characteristics of infertile egg residue from the hatching industry that were applied with chitosan during different storage periods. This research was conducted experimentally by using a Completely Randomized Design (CRD) with factorial $4 \times 3$ and 3 replications each. Each replication used 3 eggs, therefore the number of eggs used is 108 eggs. The results showed that antioxidant activity experienced a decrease as the storage period increased by 3 days $52.92 \%, 6$ days $52.39 \%$ and 9 days $50.63 \%$.Chitosan application with a concentration of $0.5 \%$ showed an increase in the antioxidant activity of infertile eggs by $52.39 \%$ compared to concentrations of $0 \%(51.63 \%), 1 \%(51.86 \%)$ and $1.5 \%(52.04 \%)$. Concluded that chitosan antioxidant activity decreased as the storage period increased. The application of chitosan with a concentration of $0.5 \%$ showed an increase in the antioxidant activity of infertile egg, compared to other concentrations
\end{abstract}

Key words: Infertile egg, Chitosan, Antioxidant Activity.

\section{INTRODUCTION}

The number of infertile egg is quite large in the hatching industry. During the candling process, the number of infertile egg from hatching machine up to $26.7 \%$ of the total number of eggs in the hatching machine therefore in large-scale hatching industry the number of infertile egg can reach thousands of grains [1]. These eggs are usually removed because they only drain the power and hatcheries that should be used for fertile eggs. But infertile egg can be sold as consumption egg and for ingredients in food processing products. However, consumption of infertile egg is still low in the community. Infertile egg is susceptible to damage due to warming during the incubation periods carried out by the hatching industry. Decreased in the quality of physical characteristics, nutritional value and storage periods that are directly proportional with its role as functional food which also decreased and low the selling value of infertile egg. Previous studies [2] found that the average percentage of antioxidant activity in infertile egg decreased as the incubation time increased at 0 days at $84.58 \%, 9$ days at $77.99 \%$, and 18 days at $42.97 \%$.

One of the factors causing damage is the oxidation process. Oxidation of fats and proteins can cause damage to foodstuffs. Damage can be prevented by the presence of antioxidants, both natural antioxidants from food, added synthetic antioxidants and antioxidants obtained from processing activities. Increased storage periods and quality as well as its utilization as functional food can be increased by adding other foodstuffs that have other functional value, one of which is extracts of skin or shells from animals that contain chitosan substances. Chitosan has many benefits in various fields, including biomedicine, pharmaceutical products, food preservation, and bacterial reduction. In the field of biomedicine, chitosan can act as an antioxidant [3]. Chitosan solution contains antioxidants as proven by the ability of chitosan solutions to reduce the activity of free radicals such as hydrogen peroxide, superoxide anions and $\mathrm{Cu} 2+$ ions by binding to these free radical ions [4].

Application of different chitosan concentrations, as well as different storage periods, will affect the physical characteristics of the infertile egg. Not many studies have analyzed the role of chitosan in shrimp skin can have an influence on antioxidant activity in the infertile egg during the storage periods. This research is important to develop infertile egg-based functional foods which are added with chitosan.

\section{MATERIALS AND METHODS}

The research was conducted from March to April 2018, at the Poultry Laboratory and the Meat and Egg Laboratory of Animal Science Department, University of Hasanuddin, Makassar and collected eggs at PT. Japfa Comfeed Hatchery, Maros.

The ingredients used were infertile broiler eggs from the hatching industry with a 9-day incubation period, chitosan, clear tape, DPPH, methanol, distilled water, $2 \%$ acetic acid, alcohol, $\mathrm{HCl}$, tissue, mask, latex gloves and label paper. The equipments used in this research are injector / automatic syringe, UV-VIS spectrophotometer, test tube, measuring cup, egg drill, beaker, egg rack and stationery.

Chitosan solution was made by mixing chitosan powder $0.5 \mathrm{~g}, 1 \mathrm{~g}$ and $1.5 \mathrm{~g}$ in $100 \mathrm{ml}$ of $2 \%$ acetic acid solution with a concentration of $0.5 \%, 1 \%$, and $1.5 \%$. The mixture results are then homogenized using a stirrer [5]. The initial stage is that the egg is perforated in its air cavity, then the injection hole is cleaned using alcohol before injecting, each chitosan solution is injected as much as $0.5 \mathrm{ml}$ into the egg slowly, in the next hole is homogenized with a slow-motion forming the 
number eight to be homogeneous. Then close the egg hole with clear tape [6]. The injected and injection-free eggs are then stored at room temperature for 3,6 and 9 days. At the time of storage, the position of the egg must be reversed, the air cavity below so that the chitosan solution can spread well [6].

Antioxidant Activity Testing with DPPH Method (1,1-diphenyl-2-picrylhydrazyl) [7]. DPPH was weighed as much as $0.008 \mathrm{~g}$ then diluted into $50 \mathrm{ml}$ of methanol. The control absorbance was obtained from DPPH dilution with several concentrations. Dilution is done by adding DPPH to $9 \mathrm{ml}$ of methanol with concentrations of $50 \mu 1,60 \mu 1,70 \mu 1,80 \mu 1,90 \mu 1$ and $100 \mu 1$, respectively. Solution uptake was measured using a Spectrophotometer UV-VIS at a wavelength of 515 $\mathrm{nm}$. A sample of $1 \mathrm{ml}$ was diluted into $9 \mathrm{ml}$ of methanol and homogenized using vortex. Dilution from $10^{-1}$ to $10^{-5}$. Each dilution was tested as much as $0.2 \mathrm{ml}$ of sample solution into the test tube and added DPPH as much as $3.8 \mathrm{ml}$ and $0.2 \mathrm{ml}$ of methanol. The sample mixture was homogeneous using vortex and left for 60 minutes in a dark room. The uptake of the solution was measured using a spectrophotometer UV-VIS at a wavelength of $515 \mathrm{~nm}$. The amount of antioxidant activity is calculated by the formula:

DPPH Radical Scavenging Effect $(\%)=\underline{(\mathrm{A} \text { DPPH }- \text { A sample })} \times 100$

\section{ADPPH}

Information:

ADPPH

A sample

: Absorbance DPPH

: Absorbente sample

The data obtained were analyzed variously based on a Completely Randomized Design (CRD) factorial pattern 4 x 3 with 3 replications. Analysis of the variance is based on the design mathematical model used, as follows:

$Y_{i j k}=\mu+\alpha_{i}+\beta_{j}+(\alpha \beta)_{i j}+\varepsilon_{i j k}$

$\mathrm{i}=1,2,3,4$

$\mathrm{j}=1,2,3$

$\mathrm{k}=1,2,3$

Information:

$\mathrm{Y}_{\mathrm{ijk}}$ : Observation value on the $\mathrm{i}$-chitosan concentration factor and the $\mathrm{j}$-storage periods factor for the $\mathrm{k}$ replication.

$\mu \quad:$ General middle value

$\alpha_{\mathrm{i}}:$ Effect of the i-chitosan concentration factor

$\beta_{\mathrm{j}} \quad$ : Effect of the j-length of storage periods factor

$(\alpha \beta)_{\mathrm{ij}}$ : Interaction between the $\mathrm{i}$-chitosan concentration factor and the $\mathrm{j}$-storage periods

$\epsilon_{\mathrm{ijk}} \quad$ : Effect of defects in the i-chitosan concentration factor and the j-storage periods on the k-replication

Then the data processing is done by using SPSS 16 program. Then if the treatment shows a real effect, it is continued with Duncan test [8].

\section{RESULT AND DISCUSSION}

Analysis of randomize showed that the application of chitosan to infertile egg with different storage periods had a very significant effect $(\mathrm{P}<0.01)$ on antioxidant activity. There is an interaction between them.

Table 1: Antioxidant Activity Value (\%) of infertile egg by giving chitosan during different storage periods

\begin{tabular}{|l|l|l|l|l|}
\hline \multirow{2}{*}{ Concentration (\%) } & Storage Periods (Days) & 6 & 9 & Average \\
\cline { 2 - 5 } & 3 & $53,10 \pm 0,36$ & $50,20 \pm 0,10$ & $51,63 \pm 1,28^{\mathrm{a}}$ \\
\hline 0 & $51,58 \pm 0,29$ & $53,16 \pm 0,40$ & $51,45 \pm 0,37$ & $52,39 \pm 0,80^{\mathrm{c}}$ \\
\hline 0,5 & $52,56 \pm 0,05$ & $51,40 \pm 0,20$ & $50,79 \pm 0,11$ & $51,86 \pm 1,18^{\mathrm{b}}$ \\
\hline 1,5 & $53,40 \pm 0,10$ & $51,90 \pm 0,59$ & $50,08 \pm 0,02$ & $52,04 \pm 1,80^{\mathrm{b}}$ \\
\hline Average & $54,15 \pm 0,17$ & $52,39 \pm 0,87^{\mathrm{b}}$ & $50,63 \pm 0,59^{\mathrm{c}}$ & $51.9797 \pm 1,29$ \\
\hline
\end{tabular}

Information: Different superscripts in the same column or row show significant differences $(\mathrm{P} \leq 0.05)$.

Based on further tests (Duncan), showed that different antioxidant activity decreased significantly during storage periods increased. The decreased with storage periods occur because antioxidant activity works hard to inhibit protein oxidation that occurs in eggs. While the antioxidant activity in the infertile egg by giving chitosan with a concentration of $0.5 \%$ showed significantly increased differences in the antioxidant activity of infertile egg. This showed that at a concentration of $0.5 \%$ chitosan was able to work in inhibiting oxidation better compared to other concentrations. According to [4] stated that chitosan contains antioxidants as proven by the ability of chitosan solutions to reduce the activity of free radicals such as hydrogen peroxide, superoxide anions, and Cu $2+$ ions by binding to these free radical ions. This is supported by research [9] also states that chitosan contains antioxidants that can help increase the storage periods of oxidized susceptible products. Addition of chitosan solution $0.2 \%, 0.5 \%$, and $1.0 \%$ to salmon meat can reduce fat oxidation. Antioxidants in the ingredients will capture free radicals (DPPH) through the mechanism of donating hydrogen atoms. The more DPPH is captured, the better the antioxidant is in inhibiting oxidation [10].

The results of the research [11] showed that astaxanthin was the largest composition of carotenoid pigments in crustaceans (lobster, crab, and shrimp). Carotenoids are pigments that give yellow, orange or red color to fish and shrimp [12]. Carotenoids which have antioxidant activity are needed to reduce the activity of free radicals [13]. Amino groups (NH2) and hydroxyl groups $(\mathrm{OH})$ in chitosan are the key functional groups of antioxidant activity in chitosan [14]. Amine groups are NH2 in chitosan which work to capture free radical [15]. Chitosan consists of three reactive functional groups, amino groups both primary and secondary hydroxyl groups [14]. Amino groups $(\mathrm{NH} 2)$ and hydroxyl groups $(\mathrm{OH})$ are the key functional groups of antioxidant activity in chitosan [3].

Antioxidant activity is one of the famous chitosan functions. Many studies have shown that chitosan inhibits reactive oxygen species (ROS) and prevents lipid oxidation in food systems and biology [9]. Chitosan can rearrange free radicals or strip off metal ions from hydrogen donations or single electron pairs [16]. The groups of hydroxyl $(\mathrm{OH})$ and amino $(\mathrm{NH})$ in chitosan are the main functional groups for their antioxidant activity but are difficult to separate due to the chitosan semi-crystalline structure with strong hydrogen bonds [16].

[7] stated that lower concentrations of antioxidants resulted in higher antioxidant activity. Based on research conducted by [7] it was found that the antioxidant concentration in free-range chicken egg was higher than that of broiler because of its high protein content, but this resulted in lower antioxidant activity. The group of phenols and double bonds determine the concentration produced from antioxidants.

The results of the research (Fig. 1) showed that there was an interaction $(\mathrm{P}<0.01)$ between the concentration of chitosan and the storage periods on antioxidant activity. Infertile egg which is given chitosan with different concentrations has decreased antioxidant activity at 9 days storage. This happens due to storage that causes oxidation in infertile egg, therefore it forces antioxidants to move harder in inhibiting oxidation.

Antioxidants are compounds that susceptible to oxidation in the presence of effects such as light, heat, metal peroxide or directly react with oxygen therefore the value of antioxidant activity decreases during storage [17]. As with [18], antioxidants will decrease during storage. This is because the environmental condition of storage room temperature can not be controlled such as the presence of heat and oxygen, in addition it is added that antioxidant activity has decreased due to the deterioration of physical, chemical and biological conditions, especially in the destruction of secondary metabolites due to indirect light [19].

Chitosan is a class of carbohydrate compounds, chitosan developed and produced in Indonesia comes from marine fishery waste. Chitosan contains pigments which are useful as colorants for egg yolks [20]. According to [16] chitosan solution has antioxidant activity, the mechanism formed is the binding of free radicals by chitosan, $\mathrm{OH}$-radical group from the lipid oxidation process can react with hydrogen ions from the ammonium ion group (NH3 +) in chitosan to produce a more stable molecular and produce antioxidant compounds. 
In a research conducted by [21] it was found that the antioxidant activity of dragon fruit extract that is given chitosan during the storage periods was higher at $57.33 \%$ compared to the results of research conducted on infertile egg that is given chitosan during storage periods. Another research conducted by [22] that salted egg with the addition of empirical ginger extract (50\%) had antioxidant content of $24.75 \%$ during 2 days storage and $16.63 \%$ during 4 days storage. Increased storage period up to 14 consecutive days decreased the antioxidant activity up to $3.08 \%$. Antioxidant have variety mechanisms which is radical scavenging, link metals, enzymes inhibition, lipid oxidation and pull of single oxygen [23,24]. Other antioxidant capabilities include controlling lipid levels in blood and being antimutagenic, having anti-inflammatory and anti-diabetic activities, etc [25,26].

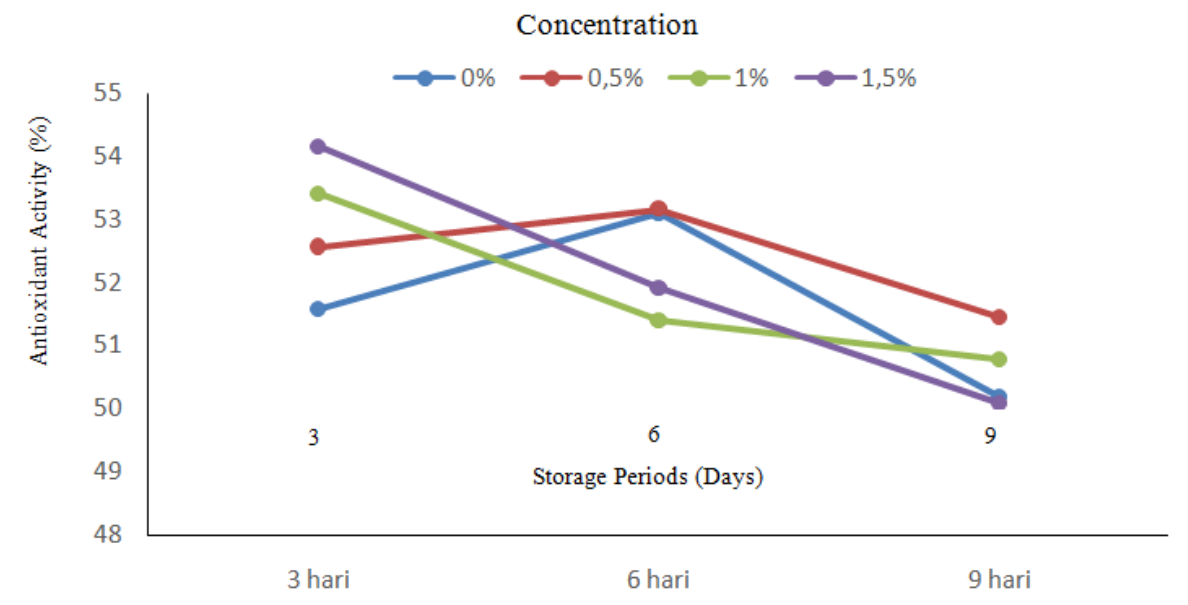

Fig. 1: Interaction between antioxidant activity and chitosan concentration during different storage periods in infertile egg

Conclusion:

Based on the results and discussion of the research that has been done, it can be concluded that the antioxidant activity decreased as the storage period increased. The application of chitosan with a concentration of $0.5 \%$ showed an increase in the antioxidant activity of infertile egg, compared to other concentrations.

\section{ACKNOWLEDGEMENT}

The authors would like to thank the Rector of University of Hasanuddin, Prof. Dr. Dwia Aries Tina Pulubuhu M.A. and Post Graduate Program of Animal Science Department, University of Hasanuddin. And also thanks to author's supervisor and co-supervisor. Special thanks to PT. Japfa Comfeed Hatchery, Maros for their support in providing research materials. Other thanks to the technicians in the Meat and Egg Laboratory University of Hasanuddin for chemicalsanalysis and thanks to the Poultry Laboratory Assistant Team, University of Hasanuddin for making research samples.

\section{REFERENCES}

[1] Almunifah, Maisaroh, 2014. Functional properties of broiler eggs and their application in the manufacture of sponge cake products. Thesis. University of Gadjah Mada. Yogyakarta.

[2] Ubba, E.T., 2015. Potential antioxidants in infertile egg that is selected based on different incubation times. Thesis. University of Hasanuddin. Makassar.

[3] Rajalakshmi, A., N. Krithiga and A. Jayachitra, 2013. Antioxidant activity of the chitosan extracted from shrimp exoskeleton. Middle-East Journal of Scientific Research, 16(10): 1446-1451. ISSN 1990-9233.

[4] Lin, H. and C. Chou, 2004. Antioxidative activities of water-soluble disaccharide chitosan derivatives. Food Research International, 37: 883-889.

[5] Danial, M., 2017. Incubation time and body dimensions of day old chick (doc) free-range chicken produced by giving 1-glutamine amino acid with the in ovo. Thesis. University of Hasanuddin. Makassar.

[6] Saputra, A.T., 2017. Salted egg quality in application of the combination of garlic (Allium sativum) and chili (Capsicum annum L) at different storage periods. Thesis. University of Hasanuddin. Makassar.

[7] Nahariah, A.M., E. Legowo, A. Abustam dan, Hintono, 2014. Antioxidant Activity and Antihypertension of "Pan Drying" White Flour Egg at Different Temperatures and Drying Times. National Seminar on Optimization of Local Resources in Technology-Based Citizen Farms. Animal Science Faculty of University of Hasanuddin. Makassar.

[8] Gaspersz, V., 1991. Experimental Design Method. Armico. Bandung.

[9] Kim, K.W. and R.L. Thomas, 2007. Antioxidative activity of chitosans with varying molecular weights. Food Chemistry. 101(1): 308-313.

[10] Anita, S., 2009. Study of Physico-Chemical Properties, Functional Properties of Carbohydrates, and Antioxidant Activity of Coma Bean Sprouts Flour (Lablab purpureus (L.) sweet). Thesis. Bogor Agricultural Institute. Bogor.

[11] Babu, C.M., R. Chakrabartib and K.R.S. Sambasivarao, 2008. Enzymatic isolation of carotenoidproteincomplex from shrimp headwaste and its use as a source ofcarotenoids. Swiss Soc. of Food Sci. and Technol, 41: 227-235.

[12] Ciapara, H., F. Vanezuela and F.M. Goycoolea, 2006. Astaxanthin: a review of itschemistry and applications. Critc. Rev. in Food Sci. and Nutr., 46: 185196.

[13] Shui, G., S.P. Wong, L.P. Leong, 2004. Characterization of antioxidants andchange of antioxidant levels during storage of manilkara zapota 1. J. Agricultural and Food Chem., 52: 7834-7841.

[14] El-fattah, H.M.A., Z.M. Abdel-Kader, E.A. Hassnin, M.K.A. El-rahman and L.E. Hassan, 2013. Chitosan as a hepato-protective agent against single oral dose of dioxin. Journal of Environmental Science, Toxicology and Food Technology, 7(3): 11-17.

[15] Xie, W., P. Xu, W. Wang and Q. Liu, 2002. Preparation and antibacterialactivity of a water-soluble chitosanderivative. Carbohydrate Polymer, 50: 35-40.

[16] Xie, W., P. Xu and Q. Liu. 2001. Antioxidant activity of water-soluble chitosan derivatives. Bioorganic and Medicinal Chemistry Letters, 11(13): 1699-1701.

[17] Farikha, I.N., C. Anam, dan E. Widowati, 2013. Effect of type and concentration of natural stabilizers on physicochemical characteristics of red dragon fruit extract (Hylocereus polyrhizus) during storage. Journal of Food Technology, 2(1): 30-38.

[18] Rachmawati, Deviani, Suriani, 2009. Effect of temperature and storage on vitamin C content on white cayenne pepper (Capsicum frustenscens). Journal of Biology, Faculty of Mathematics and Natural Sciences, University of Udayana, 13(2): 36-40.

[19] Wulandari, Z., 2004. Physicochemical and total microbial properties of salted duck eggs from different salting techniques and storage periods. Animal Husbandry Media, Journal of Animal Science and Technology, 27(2): 38-45. ISSN 0126-0472.

[20] Kusumaningsih, T., A. Maskur and U. Arief, 2003. The making of chitosan from chitin snail shell (achatina fulica). J. Pharmacol. Biol. Sci., 2(2): 64-68.

[21] Ratnayani, K., A.A.I.A. Mayun Laksmiwati Dan N.P.I. Septian, 2012. Total phenolic compounds in randu honey and kelengkeng honey and free antiradical activity test with dpph (difenilpikril hidrazil) method. Journal of Chemistry, 6(2): 163-168. 
[22] Leitasari, F.Y., 2012. Effect of the addition of empirical ginger (Zingiber officinale Rose) extract on antioxidant activity and antibacterial activity on salted eggs during storage with wet salting method. Thesis. University of Sebelas Maret. Surakarta.

[23] Cos, P., T. De Bruyne, N. Hermans, S. Apers, D. Vanden Berghe and A.J. Vlietinck, 2003. Proanthocyanidins in Health Care:Current and New Trends.Curre.Current Medicinal Chemistry, 10: 1345-1359.

[24] Salih, N.M., Z.S. Lazim and R.J. Kadim, 2017. Quantification of phenols and antioxidant activity for Iraqi walnut husk. American-Eurasian Journal of Sustainable Agriculture, 11(3): 14-19.

[25] Seal, T., 2016. Quantitative HPLC analysis of phenolic acids, flavonoids and ascorbic acid in four different solvent extracts of two wild edible leaves, Sonchus arvensis and Oenanthe linearis of North-Eastern region in India . J. App. Pharm. Sci., 6 (02): 157-166.

[26] Kavak, Dilek Demirbuker, 2017. Optimization of extraction time, temperature and solvent concentration for the antioxidant activity and total phenolic content of the Cydonia oblonga Mill. Leaves. American-Eurasian Journal of Sustainable Agriculture, 11(6): 1-16. 